\title{
Emission-Induced Nonlinearities in the Global Aerosol System: Results from the ECHAM5-HAM Aerosol-Climate Model
}

\author{
Philip Stier,* Johann Feichter, and Silvia Kloster \\ Max Planck Institute for Meteorology, Hamburg, Germany
}

Elisabetta Vignati and Julian Wilson

Institute for the Environment and Sustainability, European Commission Joint Research Centre, Ispra, Italy

(Manuscript received 22 November 2004, in final form 12 October 2005)

\section{ABSTRACT}

\begin{abstract}
In a series of simulations with the global ECHAM5-HAM aerosol-climate model, the response to changes in anthropogenic emissions is analyzed. Traditionally, additivity is assumed in the assessment of the aerosol climate impact, as the underlying bulk aerosol models are largely constrained to linearity. The microphysical aerosol module HAM establishes degrees of freedom for nonlinear responses of the aerosol system. In this study's results, aerosol column mass burdens respond nonlinearly to changes in anthropogenic emissions, manifested in alterations of the aerosol lifetimes. Specific emission changes induce modifications of aerosol cycles with unaltered emissions, indicating a microphysical coupling of the aerosol cycles. Anthropogenic carbonaceous emissions disproportionately contribute to the accumulation mode numbers close to the source regions. In contrast, anthropogenic sulfuric emissions less than proportionally contribute to the accumulation mode numbers close to the source regions and disproportionately contribute in remote regions. The additivity of the aerosol system is analyzed by comparing the changes from a simulation with emission changes for several compounds with the sum of changes of single simulations, in each of which one of the emission changes was introduced. Close to the anthropogenic source regions, deviations from additivity are found at up to $30 \%$ and $15 \%$ for the accumulation mode number burden and aerosol optical thickness, respectively. These results challenge the traditional approach of assessing the climate impact of aerosols separately for each component and demand for integrated assessments and emission strategies.
\end{abstract}

\section{Introduction}

Atmospheric aerosol, defined as a suspension in air of liquid or solid particles, plays an important role in the global climate system. Aerosol particles modify the global radiation budget directly, by scattering and absorption (Ångström 1962; McCormic and Ludwig 1967), as well as indirectly, by the modification of cloud properties. An increase of aerosols acting as cloud condensation nuclei $(\mathrm{CCN})$ yields in higher cloud droplet number concentrations (CDNCs) with smaller radii, increasing the cloud albedo (Twomey 1974, 1977), re-

\footnotetext{
* Current affiliation: California Institute of Technology, Pasadena, California.

Corresponding author address: Philip Stier, California Institute of Technology, 1200 E. California Blvd., Pasadean, CA 91125. E-mail: philip.stier@caltech.edu
}

ferred to as the first indirect effect. Higher CDNC also can potentially decrease the precipitation efficiency resulting in a longer cloud lifetime and a subsequent increase of the planetary albedo (Albrecht 1989), referred to as the second indirect effect. In contrast, absorbing aerosols heat the atmosphere, potentially evaporating cloud droplets (Graßl 1975; Hansen et al. 1997), and decreasing the planetary albedo, referred to as the semidirect effect. Suitable aerosols, when acting as ice nuclei, can enhance the precipitation formation in mixed phase clouds (Lohmann 2002), decreasing the cloud lifetime and therefore the planetary albedo. Modulation of solar radiation by aerosol scattering and absorption affects the surface energy balance and therefore the hydrological cycle (Roderick and Farquhar 2002; Liepert et al. 2004; Feichter et al. 2004). Furthermore, heterogeneous reactions on the aerosol surface and in liquid aerosol particles interact with the chemistry of the atmosphere (Crutzen 1996; Ravishan- 
kara 1997; Andreae and Crutzen 1997; Emmons et al. 2003), affecting the radiative effects of chemical species. Additionally, the deposition of aerosols in the ocean plays an important role in the biogeochemical cycle of the oceans (Johnson et al. 1997; Vink and Measures 2001) with potential feedbacks to the climate system via the emissions of aerosol precursors such as dimethyl sulfide (DMS) (Charlson et al. 1987).

Nevertheless, the quantitative evaluation of these aerosol effects is still insufficient (e.g., Penner et al. 2001; Ramanathan et al. 2001; Kinne et al. 2005). One reason for this is the inherent complexity of the global aerosol system. Aerosols and their precursors originate from all compartments of the earth system. A large number of aerosol compounds are observed, covering a wide range of compositions and mixing states as well as orders of magnitude in size (e.g., Murphy et al. 1998; Bates et al. 1998; Seinfeld et al. 2004). The other main reason for the insufficient understanding of the global aerosol system is that the short lifetime of aerosols causes large spatiotemporal inhomogeneities. Thus, in situ observations provide the most detailed insight into the aerosol system but are representative of limited spatial and temporal scales. Remote sensing data from ground-based lidar and sun photometers provide valuable information but suffer from sampling limitations as well. Up to now, operational remote sensing data from space only provide integral aerosol properties and retrievals rely on a priori information about the aerosol system and internal aerosol models.

Global aerosol models can help to increase the understanding about the complex aerosol system for past, present, and future conditions. Furthermore, they permit us to identify the effects of specific aerosol components and aerosol sources on the climate system.

The first global aerosol models simulated the distribution of the mass of one of the major aerosol components: sulfate (SU), black (elemental) carbon (BC), particulate organic matter (POM), sea salt (SS), and mineral dust (DU). Langner and Rhode (1991), Feichter et al. (1996), and Rasch et al. (2000) simulated the global sulfur cycle. A range of studies (e.g., Cooke and Wilson 1996; Liousse et al. 1996; Cooke et al. 1999) simulated the distribution of carbonaceous aerosols. The mineral dust cycle has been investigated, for example, in Tegen and Lacis (1996) and Ginoux et al. (2001) and the sea salt distribution has been investigated, for example, in Guelle et al. (2001). Consecutively, global aerosol models incorporated more aerosol components as external mixtures (Haywood et al. 1997; Lohmann et al. 1999; Chin et al. 2002). However, in order to derive the aerosol radiative effects and also for the parameterization of the sink processes, information on the aerosol composition, mixing state, and size distribution is essential. The size distribution of single aerosol components has been investigated, for example, in Tegen and Lacis (1996), predicting the evolution of externally mixed dust size classes with size-dependent sources and sinks. Chuang and Penner (1995) and Chuang et al. (1997) approximated the aerosol size distribution and mixing state adding sulfate by condensation and cloud processing to prescribed ambient aerosol size distributions.

The complexity of the processes and computational constraints caused a bifurcation in the model development. On the one hand models with advanced chemistry and thermodynamics evolved (e.g., Nenes et al. 1998), with a focus on the chemical composition. On the other hand microphysical models developed with a focus on the prediction of the size distribution and with less detail on the aerosol composition. Higher-resolution sectional aerosol models provide a detailed description of the aerosol size distribution. Adams and Seinfeld (2002) simulate the size distribution of sulfate aerosol with a 30-bin sectional microphysical aerosol model. However, also the aerosol mixing state affects the microphysical, chemical, and radiative properties of aerosols and therefore their cycling and climatic effects. The computational burden of multicomponent sectional aerosol models with size-resolved description of the mixing state is with current computational resources too demanding for long-term transient climate simulations of the global aerosol system. Up to now, only a few global aerosol models suitable for long-term integrations simulate the size distribution and mixing state of interacting multicomponent aerosols (see Textor et al. 2005). The application of computationally efficient modal aerosol microphysical schemes maintains the balance in complexity between the numerous processes in general circulation models and provides the basis for long-term simulations. Wilson et al. (2001) represent the size distribution in a multicomponent aerosol model by a superposition of eight partly interacting lognormal modes. Ghan et al. (2001a,b) use an interactive modal size-segregated multicomponent module to estimate the direct and indirect radiative aerosol forcing. In Stier et al. (2005) we introduced the aerosol module HAM of the Max Planck Institute Earth System Model (MPI-ESM). In HAM the aerosol distribution is represented by an ensemble of interacting internally and externally mixed lognormal aerosol modes. The sink processes as well as the aerosol optical properties are calculated in dependence of size and composition.

As it is now widely accepted that aerosols exert a distinct impact on regional- and global-scale climate 
(Penner et al. 2001; Heintzenberg et al. 2003) and that enhanced aerosol concentrations pose a risk to human health (Dockery et al. 1993; Lippmann 2000), emission reduction strategies for aerosols and their precursors have become of fundamental importance. Earlier, acidification-related aerosol precursors were mitigated. Particulate mass has now become a criteria pollutant (e.g., EC 1999; WHO 2003). It is widely assumed that the responses of the aerosol system are linear, so that the changes in the emissions are linearly reflected in the aerosol distribution. However, changes in emissions of aerosols or their precursors can potentially induce nonlinear responses of the global aerosol system. Observations indicate that the mixing state of the global aerosol system shows a large internally mixed contribution with varying ratios among constituents (e.g., Murphy et al. 1998; Bates et al. 1998; Seinfeld et al. 2004). Thus, one can hypothesize that changes in the emissions of individual aerosol compounds or their precursors can affect the chemical and microphysical aging capacity of the atmosphere, resulting in a nonlinear response of aerosol populations with a coherence among the individual aerosol compounds. Chemical aging in this context refers to the modification of aerosol properties via heterogeneous reaction on the aerosol surface or chemical reactions within the aerosol particles. Microphysical aging refers to growth and modification of aerosols by coagulation with other aerosol particles, condensation of gaseous compounds on the aerosol surface, and by cloud processing, affecting their size distribution, solubility, and radiative properties. For secondary aerosols, emission changes can also induce shifts in chemical equilibria and modify the oxidizing capacity of the atmosphere, nonlinearly affecting the aerosol system (e.g., Chin et al. 2000). Shifts in the relative emission strength of the aerosol compounds can affect the phase partitioning of semivolatile aerosol species, resulting in nonlinear responses of the aerosol mass (West et al. 1999). Spatially inhomogeneous emissions changes can introduce nonlinearities in the mass response as the aerosol sink processes and resulting lifetime vary regionally and, in particular for the secondary particles, by source type and formation pathway (Graf et al. 1997). Additionally, as highlighted in Wilson et al. (2001), one can expect that the response of the aerosol numbers will be nonlinear, even when the response of the aerosol mass is linear, as secondary particle formation and growth and sink processes are highly nonlinear functions of the aerosol and aerosol precursor mass.

The representation of these processes in global aerosol models is a challenging task. The majority of current global aerosol models, bulk mass models without prog- nostic treatment of size distribution and mixing state, can only capture nonlinearities due to spatially inhomogeneous emissions and due to shifts in chemical equilibria. Some bulk models parameterize aging timedependently, neglecting spatial and temporal variations in the aging capacity, for example, because of anthropogenic pollution. Thermodynamical models can additionally account for the nonlinear partitioning effects. Global microphysical aerosol models are required to scrutinize the effect of variations of emissions on the aerosol aging and cycling and the aerosol size distribution and numbers, as well as on the coherence among the aerosol cycles. The microphysical approach of HAM, including the processes coagulation, condensation, nucleation, sulfur chemistry, and water uptake, as well as size and composition-dependent sink processes for the ensemble of lognormal modes allows us to investigate the listed nonlinearities, except for the phase partitioning effect.

It has to be emphasized that many processes and parameters in global aerosol models, explicitly predicted as in this study or highly parameterized as in most previous studies, are subject to nonnegligible uncertainties. Nonetheless, global aerosol models provide the unique possibility to analyze the sensitivity of the global aerosol system to external perturbations under well-constrained conditions and allow insight into the underlying mechanisms.

In this study we analyze the response of the global aerosol system to changes in anthropogenic emissions of aerosols and their precursors with a particular focus on nonlinearities and the coherence among the aerosol cycles.

Section 2 describes the ECHAM5-HAM aerosolclimate model as part of the MPI-ESM and the investigated emission scenarios. The analysis of the response of the aerosol system to the anthropogenic emission changes is presented in section 3 . Section 4 concludes and summarizes the main findings.

\section{Model description}

\section{a. The aerosol-climate model ECHAM5-HAM}

In the current setup, the MPI-ESM consists of the following interactively coupled submodels: the atmospheric general circulation model ECHAM5 (Roeckner et al. 2003, 2006), the Max Planck Institute Ocean General Circulation Model (MPI-OM) (Marsland et al. 2003), the surface and vegetation model JSBACH (Raddatz et al. 2006, manuscript submitted to Climate Dyn.), the atmospheric aerosol model HAM (Stier et al. 2005), the atmospheric chemistry model MOZECH 
TABLE 1. Modal structure and possible mixing state configurations of HAM; $N_{i}$ denotes the aerosol number of the mode $i$ and $M_{i}^{j}$ denotes the mass of compound $j \in\{\mathrm{SU}, \mathrm{BC}, \mathrm{POM}, \mathrm{SS}, \mathrm{DU}\}$ in mode $i$.

\begin{tabular}{lll}
\hline \hline \multicolumn{1}{c}{ Modes } & \multicolumn{1}{c}{ Soluble/mixed } & Insoluble \\
\hline Nucleation & $N_{1}, M_{1}^{\mathrm{SU}}$ & $N_{5}, M_{5}^{\mathrm{BC}}, M_{5}^{\mathrm{POM}}$ \\
Aitken & $N_{2}, M_{2}^{\mathrm{SU}}, M_{2}^{\mathrm{BC}}, M_{2}^{\mathrm{POM}}$ & $N_{6}, M_{6}^{\mathrm{DU}}$ \\
Accumulation & $N_{3}, M_{3}^{\mathrm{SU}}, M_{3}^{\mathrm{BC}}, M_{3}^{\mathrm{POM}}, M_{3}^{\mathrm{SS}}, M_{3}^{\mathrm{DU}}$ & $N_{7}, M_{7}^{\mathrm{DU}}$ \\
Coarse & $N_{4}, M_{4}^{\mathrm{SU}}, M_{4}^{\mathrm{BC}}, M_{4}^{\mathrm{POM}}, M_{4}^{\mathrm{SS}}, M_{4}^{\mathrm{DU}}$ & \\
\hline
\end{tabular}

(S. Rast et al. 2004, personal communication), and the Hamburgh Oceanic Carbon Cycle Model (HAMOCC5) (Wetzel et al. 2006). In this study we use a submodel of the MPI-ESM, the combined ECHAM5-HAM aerosolclimate model, described in detail in Stier et al. (2005).

\section{1) The ECHAM5 GENERAL CiRCULATiON} MODEL

The atmospheric general circulation model ECHAM5 is the fifth-generation climate model developed at the Max Planck Institute for Meteorology, evolving from the model of the European Centre for Medium-Range Weather Forecasts (ECMWF). ECHAM5 solves prognostic equations for vorticity, divergence, surface pressure, and temperature expressed in terms of spherical harmonics with a triangular truncation. Nonlinear processes and the physical parameterizations are solved on a corresponding Gaussian grid. Water vapor, cloud liquid water, cloud ice, and trace components are transported in gridpoint space with a flux form semiLagrangian transport scheme (Lin and Rood 1996). ECHAM5 contains a new microphysical cloud scheme (Lohmann and Roeckner 1996) with prognostic equations for cloud liquid water and ice. Cloud cover is predicted with a prognostic-statistical scheme solving equations for the distribution moments of total water (Tompkins 2002). Convective clouds and convective transport are based on the mass flux scheme of Tiedtke (1989), with modifications by Nordeng (1994). The solar radiation scheme (Fouquart and Bonnel 1980) has four spectral bands, one for the visible and ultraviolet, and three for the near infrared. The longwave radiation scheme (Mlawer et al. 1997; Morcrette et al. 1998) has 16 spectral bands. ECHAM5 has the capability to perform nudged simulations, that is, to relax the prognostic variables toward an atmospheric reference state, such as forecast or reanalysis data from operational weather forecast models.

\section{2) The Aerosol module HAM}

The microphysical aerosol module HAM (Stier et al. 2005) predicts the evolution of an ensemble of seven interacting internally and externally mixed lognormal aerosol modes. In the current setup, the components sulfate, black carbon, particulate organic matter, sea salt, and mineral dust are included. The aerosol mixing state is prognosed within the possible mixing state configurations illustrated in Table 1. The modes are composed either of compounds with no or low solubility, henceforth denoted as insoluble mode, or by an internal mixture of insoluble and soluble compounds, henceforth denoted as soluble mode. The main components of HAM are the microphysical core M7 (Vignati et al. 2004), an emission module, a sulfur chemistry scheme (Feichter et al. 1996), a deposition module, and a module to calculate the aerosol radiative properties.

The microphysical core M7 calculates the coagulation among the modes, the condensation of gas-phase sulfuric acid on the aerosol surface, the binary nucleation of sulfate, and the water uptake. Emissions of DMS are calculated interactively from prescribed DMS seawater concentrations (Kettle and Andreae 2000). Dust emissions are calculated following Tegen et al. (2002) and sea salt emissions after Schulz et al. (2004). The emissions of anthropogenic and volcanic $\mathrm{SO}_{2}$, of terrestrial DMS, of BC, and of POM are based on the Aerosol Model Intercomparison Experiment (AEROCOM; http://nansen.ipsl.jussieu.fr/AEROCOM/) emission inventories (Dentener et al. 2006) for the years 1750 and 2000. Following the recommendations of AEROCOM, $2.5 \%$ of the total $\mathrm{SO}_{2}$ emissions are assumed to be in the form of primary sulfate. Initially, dust and black carbon emissions are assumed insoluble. Sixty-five percent of all POM emissions are assumed soluble (MayolBracero et al. 2002) and emitted in the respective soluble mode, and the insoluble fraction is emitted in the insoluble Aitken mode. The insoluble fraction of secondary organic aerosol (SOA) is assumed to condense on the insoluble Aitken mode and the soluble fraction on the soluble Aitken and accumulation modes at the point of emission. For the conversion of the carbon mass of POM into the total mass of POM, a factor of 1.4 is applied.

The sink processes dry deposition, sedimentation, and wet deposition as well as the aerosol optical properties are parameterized with dependence on size and 
TABLE 2. Emission scenarios used for the simulations.

\begin{tabular}{cc}
\hline \hline REF & $\begin{array}{c}\text { Reference without } \\
\text { anthropogenic sulfuric emissions from fossil fuel use, industry, and biofuels } \\
\text { Reference without } \\
\text { anthropogenic carbonaceous emissions from fossil fuel use and industry } \\
\text { Combination of NAS and NAC. Reference without } \\
\text { anthropogenic sulfuric emissions from fossil fuel use, industry, and biofuels } \\
\text { and without anthropogenic carbonaceous emissions from fossil fuel use and industry } \\
\text { NA }\end{array} \quad \begin{array}{l}\text { Solely natural emissions } \\
\text { Preindustrial emissions for year } 1750\end{array}$ \\
PAT &
\end{tabular}

composition. For the wet deposition, the differentiation of the soluble and insoluble modes is introduced in form of mode-specific semiempirical scavenging parameters with reduced scavenging efficiencies for the insoluble modes (cf. Stier et al. 2005).

This setup allows the prediction of the aerosol composition, size distribution, and mixing state. As these properties in turn affect the interactively calculated sink processes and optical properties, it renders the investigation of microphysical interaction effects on the global aerosol system possible.

\section{b. Scenarios}

To investigate the microphysical coupling among the aerosol cycles and the role of specific aerosol contribu- tors, we perform a series of simulations in which we switch off the emission of the respective aerosol contributor and compare the results to a reference run with the complete emission scenario. In the simulations the large-scale meteorology is constrained to the year 2000 by nudging ECHAM5 to the 40-yr ECMWF ReAnalysis (ERA-40) data (Simmons and Gibson 2000). The nudging method permits local-scale meteorological processes, such as clouds, to respond to perturbations (Jeuken et al. 1996). We use a horizontal resolution of T63 in spectral space with a corresponding resolution of $1.8^{\circ} \times 1.8^{\circ}$ on a Gaussian grid. The vertical resolution is set to 31 levels, extending from the surface up to $10 \mathrm{hPa}$.

To isolate the effects of the different aerosol sources,

TABLE 3. Global annual aerosol and aerosol precursor emissions in $\left[\mathrm{Tg}^{-1} \mathrm{y}^{-1}\right.$ for REF, NAT, PI, NAS, NAC, and NA. Units of sulfate refer to $[\mathrm{Tg}(\mathrm{S})]$, and emissions of dust and sea salt are scaled with $10^{-1}$ and $10^{-2}$, respectively.

\begin{tabular}{|c|c|c|c|c|c|c|c|}
\hline Species & Source & REF & NAT & PI & NAS & NAC & NA \\
\hline \multirow[t]{2}{*}{ DMS } & Marine biosphere & 23.1 & 23.2 & 23.2 & 23.1 & 23.2 & 23.1 \\
\hline & Terrestrial biosphere & 0.3 & 0.3 & 0.3 & 0.3 & 0.3 & 0.3 \\
\hline \multirow[t]{3}{*}{$\mathrm{SO}_{2}$} & Volcanoes & 14.3 & 14.3 & 14.3 & 14.3 & 14.3 & 14.3 \\
\hline & Vegetation fires & 2.1 & - & 0.7 & 2.1 & 2.1 & 2.1 \\
\hline & Fossil fuel, industry, and biofuels & 54.2 & - & 0.1 & - & 54.2 & - \\
\hline Total sulfur & & 94.0 & 37.8 & 38.6 & 39.8 & 94.1 & 39.8 \\
\hline \multirow[t]{3}{*}{$\mathrm{BC}$} & Vegetation fires & 3.0 & - & 1.0 & 3.0 & 3.0 & 3.0 \\
\hline & Fossil fuel and industry & 3.0 & - & - & 3.0 & - & - \\
\hline & Biofuels & 1.7 & - & 0.4 & 1.7 & 1.7 & 1.7 \\
\hline Total BC & & 7.7 & - & 1.4 & 7.7 & 4.7 & 4.7 \\
\hline \multirow[t]{4}{*}{ POM } & Biogenic & 19.1 & 19.1 & 19.1 & 19.1 & 19.1 & 19.1 \\
\hline & Vegetation fires & 34.7 & - & 12.7 & 34.7 & 34.7 & 34.7 \\
\hline & Fossil fuel and industry & 3.4 & - & - & 3.4 & - & - \\
\hline & Biofuels & 9.1 & - & 2.2 & 9.1 & 9.1 & 9.1 \\
\hline Total POM & & 66.3 & 19.1 & 34.0 & 66.3 & 62.9 & 62.9 \\
\hline $\mathrm{DU}\left(\times 10^{-1}\right)$ & Wind driven & & & & & & \\
\hline Accumulation & & 0.8 & 0.8 & 0.8 & 0.8 & 0.8 & 0.8 \\
\hline Coarse & & 65.4 & 66.4 & 66.1 & 65.4 & 65.7 & 65.7 \\
\hline Total DU & & 66.2 & 67.2 & 66.9 & 66.2 & 66.5 & 66.5 \\
\hline $\mathrm{SS}\left(\times 10^{-2}\right)$ & Wind driven & & & & & & \\
\hline Accumulation & & 0.5 & 0.5 & 0.5 & 0.5 & 0.5 & 0.5 \\
\hline Coarse & & 49.6 & 49.7 & 49.7 & 49.5 & 49.6 & 49.6 \\
\hline Total SS & & 50.1 & 50.2 & 50.2 & 50.0 & 50.1 & 50.1 \\
\hline
\end{tabular}


we perform simulations with the full year-2000 emissions (REF) as evaluated in Stier et al. (2005), with solely natural emissions (NAT), and with preindustrial emissions for the year 1750 (PI). Additionally, we perform year-2000 simulations without $\mathrm{SO}_{2}$ emissions from fossil fuel use, industry and biofuels (NAS), without BC and $\mathrm{POM}$ emissions from fossil fuel use and industry (NAC), and a combined simulation without $\mathrm{SO}_{2}$ emissions from fossil fuel use, industry, and biofuels and without $\mathrm{BC}$ and $\mathrm{POM}$ emissions from fossil fuel use and industry (NA). The contribution of biofuels to the total sulfuric emissions is small so that the sulfuric source categories can to a first order be interpreted as fossil fuel use and an industry scenario comparable to the carbonaceous emissions. For the NAT scenario the assumption is made that emissions from vegetation fires, fossil fuel use, industry, and biofuels have a solely anthropogenic origin. Thus these emissions are not included in NAT. As a nonnegligible fraction of vegetation fires are of natural origin, ignited by lightning (Saarnak 2001), this scenario is a lower estimate of the natural emissions. An overview of the scenarios is given in Table 2, the respective emission strengths are listed in Table 3, and the zonal emission distribution is depicted in Fig. 1. It should be noted that the interactively calculated sources of DMS, sea salt, and dust are unaltered in the scenarios but show marginal variability due to variations in the local meteorological parameters, as only the large-scale meteorology is constrained by the nudging technique. To isolate the impact of the changes in aerosol emissions, for all runs the offline oxidant fields for the sulfate chemistry are used as in the REF scenario.

\section{Results}

\section{a. Response of aerosol mass}

If the response of the aerosol system were linear and decoupled, a decrease of the emission strength of a certain species should result in a reduction of the total aerosol burden of that species by the same percentage. Therefore, the lifetime of a species, defined as the ratio of the mass burden $(\mathrm{Tg})$ to sources $\left(\mathrm{Tg}\right.$ days $^{-1}$ ), should be unaffected. Distribution, burden, and lifetime of other species should not be altered. Table 4 lists the annual-mean total sources, the column burden, and the lifetime for the different scenarios and aerosol species. For sulfate the sources are the sum of $\mathrm{SO}_{2}$ in-cloud oxidation, condensation of gas-phase sulfuric acid, primary emissions, and nucleation. For the initially insoluble DU and BC and for the initially insoluble fraction of POM the microphysical aging time is given, defined as ratio of the column burden $(\mathrm{Tg})$ of the
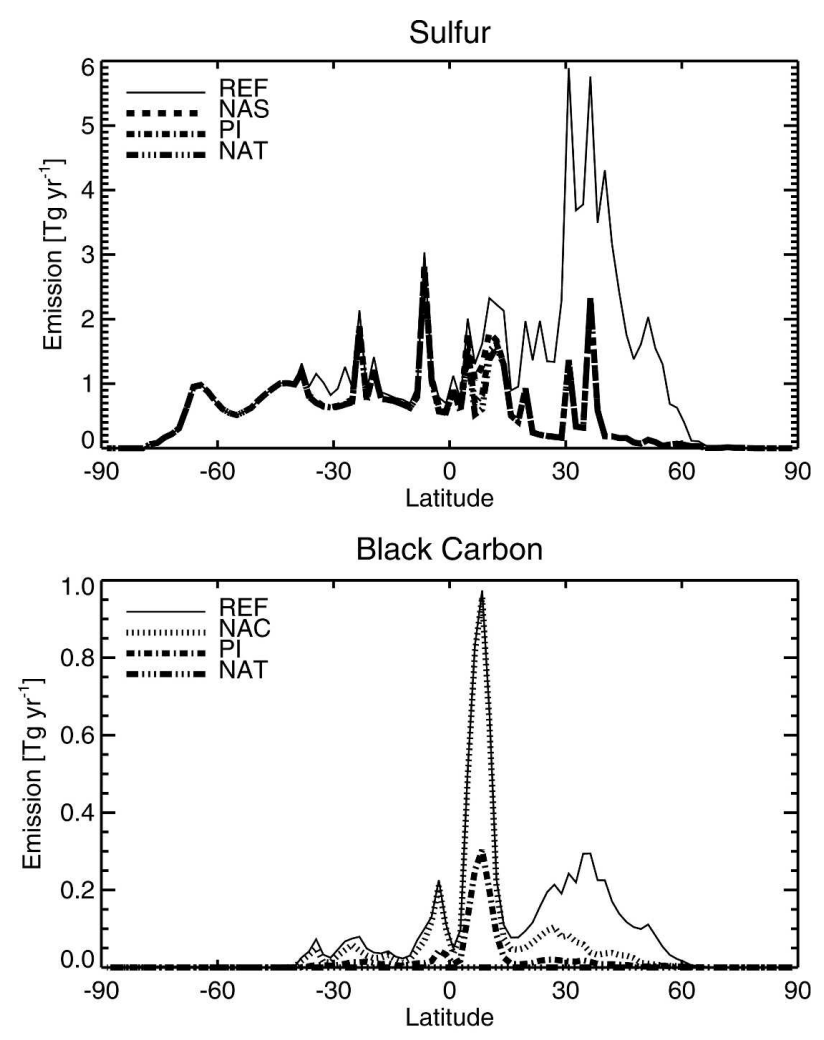

Particulate Organic Matter

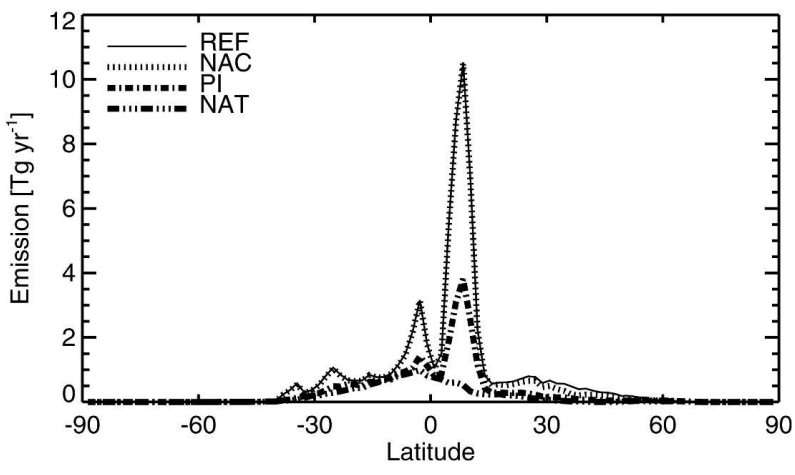

Fig. 1. Annual zonal-mean aerosol and aerosol precursor emissions $\left[\mathrm{Tg}^{-1} \mathrm{yr}^{-1}\right.$ for the reference scenario (REF), the natural (NAT), the preindustrial (PI), the scenario without $\mathrm{SO}_{2}$ emissions (NAS), and the scenario without BC and POM emissions (NAC) from fossil fuel and industry.

insoluble compound divided by the transfer to the soluble modes $\left(\mathrm{Tg}\right.$ days $\left.^{-1}\right)$. The zonal distribution of the column burdens and the percent changes with respect to the REF scenario are depicted in Fig. 2.

From Table 4 it is evident that the sea salt cycle is unaffected by the changes in anthropogenic emissions, as anthropogenic components that become attached by microphysical processes are negligible in terms of aerosol mass and sea salt is a priori soluble. Therefore, the sea salt cycle is not further investigated. 
TABLE 4. Global annual aerosol sources $\left[\mathrm{Tg} \mathrm{yr}^{-1}\right]$ and annual-mean column burdens [Tg], lifetime [days], and aging time for the insoluble fraction, for REF, NAT, PI, NAS, NAC, and NA. Units of sulfate refer to $[\mathrm{Tg}(\mathrm{S})]$, and emissions of dust and sea salt are scaled with $10^{-1}$ and $10^{-2}$, respectively.

\begin{tabular}{llcccccc}
\hline \multicolumn{1}{c}{ Species } & & REF & NAT & PI & NAS & NAC & NA \\
\hline Sulfate & Sources & 76.1 & 32.9 & 33.6 & 34.6 & 76.1 & 34.6 \\
& Burden & 0.80 & 0.38 & 0.39 & 0.41 & 0.79 & 0.41 \\
\multirow{3}{*}{ Black carbon } & Lifetime & 3.8 & 4.2 & 4.3 & 4.3 & 3.8 & 4.3 \\
& Emissions & 7.7 & - & 1.4 & 7.7 & 4.7 & 4.7 \\
& Burden & 0.11 & - & 0.03 & 0.12 & 0.08 & 0.09 \\
& Lifetime & 5.4 & - & 6.9 & 5.8 & 6.4 & 6.7 \\
Particulate organic matter & Aging time & 0.7 & - & 0.3 & 1.9 & 0.5 & 0.9 \\
& Emissions & 66.3 & 19.1 & 34.0 & 66.3 & 62.9 & 62.9 \\
& Burden & 0.99 & 0.21 & 0.46 & 1.01 & 0.95 & 0.97 \\
& Lifetime & 5.5 & 4.0 & 4.9 & 5.6 & 5.5 & 5.6 \\
Dust & Aging time & 1.1 & 0.5 & 0.9 & 2.0 & 1.0 & 1.5 \\
& Emissions $\left[\times 10^{-1}\right]$ & 66.2 & 67.2 & 66.9 & 66.2 & 66.5 & 66.5 \\
& Burden & 8.29 & 8.57 & 8.53 & 8.41 & 8.30 & 8.46 \\
& Lifetime & 4.6 & 4.7 & 4.7 & 4.6 & 4.6 & 4.6 \\
Sea salt & Aging time & 4.9 & 7.7 & 7.8 & 8.0 & 4.8 & 7.9 \\
& Emissions $\left[\times 10^{-2}\right]$ & 50.1 & 50.2 & 50.2 & 50.0 & 50.1 & 50.1 \\
& Burden & 10.45 & 10.45 & 10.44 & 10.43 & 10.44 & 10.44 \\
& Lifetime & 0.8 & 0.8 & 0.8 & 0.8 & 0.8 & 0.8 \\
\hline
\end{tabular}

For the other compounds, alterations in the aerosol lifetime are evident, indicating a nonlinear response of the aerosol mass to changes in the emissions. In all scenarios except NAC, the sulfate sources were approximately halved. The sulfate lifetime increases from 3.8 days in REF to 4.2 and 4.3 days for the NAT and the PI, NAS, and NA scenarios, respectively. It is not possible to attribute the nonlinearity solely to microphysical aging as the increase of lifetime is also consistent with the relative shift of the emissions to low-latitude source regions (Fig. 1) and to natural sources, facilitating a longer life time (Graf et al. 1997).

However, the increase of the burden and lifetime of $\mathrm{BC}$ in the scenario without anthropogenic sulfur emissions (NAS) is a clear evidence for the impact of microphysical aging and the coherence of the aerosol cycles. The reduction of the sulfate source from 76.1 $\mathrm{Tg}(\mathrm{S}) \mathrm{yr}^{-1}$ in REF to $34.6 \mathrm{Tg}(\mathrm{S}) \mathrm{yr}^{-1}$ in NAS increases the global lifetime of BC from 5.4 to 5.8 days as the reduced microphysical aging slows down the transfers of BC to the soluble modes, making it less prone to wet deposition. For POM the increase from 5.5 to 5.6 days is less pronounced, as $65 \%$ of the POM sources are already assumed soluble. The effect of aging is also reflected in the increase of the aging times of BC, POM, and DU by $164 \%, 84 \%$, and $66 \%$, respectively. The zonal distribution of the column burden shows a general increase in $\mathrm{BC}$, with the most pronounced absolute increase between $15^{\circ}$ and $40^{\circ} \mathrm{N}$, where the reduction in sulfuric emissions is strongest. For POM the change in the annual zonal-mean column burden is similar though less pronounced. For BC, POM, and DU the zonal distribution shows the strongest relative increase in the high northern latitudes, reaching $70 \%, 20 \%$, and $20 \%$, respectively. These increases are accompanied by total deposition rates increases of up to $140 \%, 60 \%$, and $20 \%$, respectively (not shown).

In the scenario without carbon emissions from fossil fuels and industry (NAC), the reduction of the total aerosol mass source is with $6.4 \mathrm{Tg} \mathrm{yr}^{-1}$ relatively small and does not significantly affect the mass burden of other aerosol cycles. However, the BC lifetime increases from 5.4 to 6.4 days. This is most likely attributable to the shift of the dominant emission source to biomass burning with maxima of the vegetation fire emissions in the dry season and injection of the emissions above the surface sinks. The aging time of $\mathrm{BC}$ and POM is slightly decreased as the insoluble $\mathrm{BC}$ and POM in the NAC scenario are predominantly coemitted with the soluble POM in the biomass-burning regions.

Conversely, the POM lifetime in the NAT and PI scenarios is decreased from 5.5 to 4.0 and to 4.9 days, respectively, as the relative contribution of emissions from non-biomass-burning sources increases. The minimum zonal-mean relative reduction of $\mathrm{BC}$ and $\mathrm{POM}$ is found around $60^{\circ} \mathrm{N}$. For POM in the PI scenario the increase due to reduced microphysical aging outweighs the decrease due to the reduced emissions, resulting in an absolute increase of POM of up to $40 \%$. 

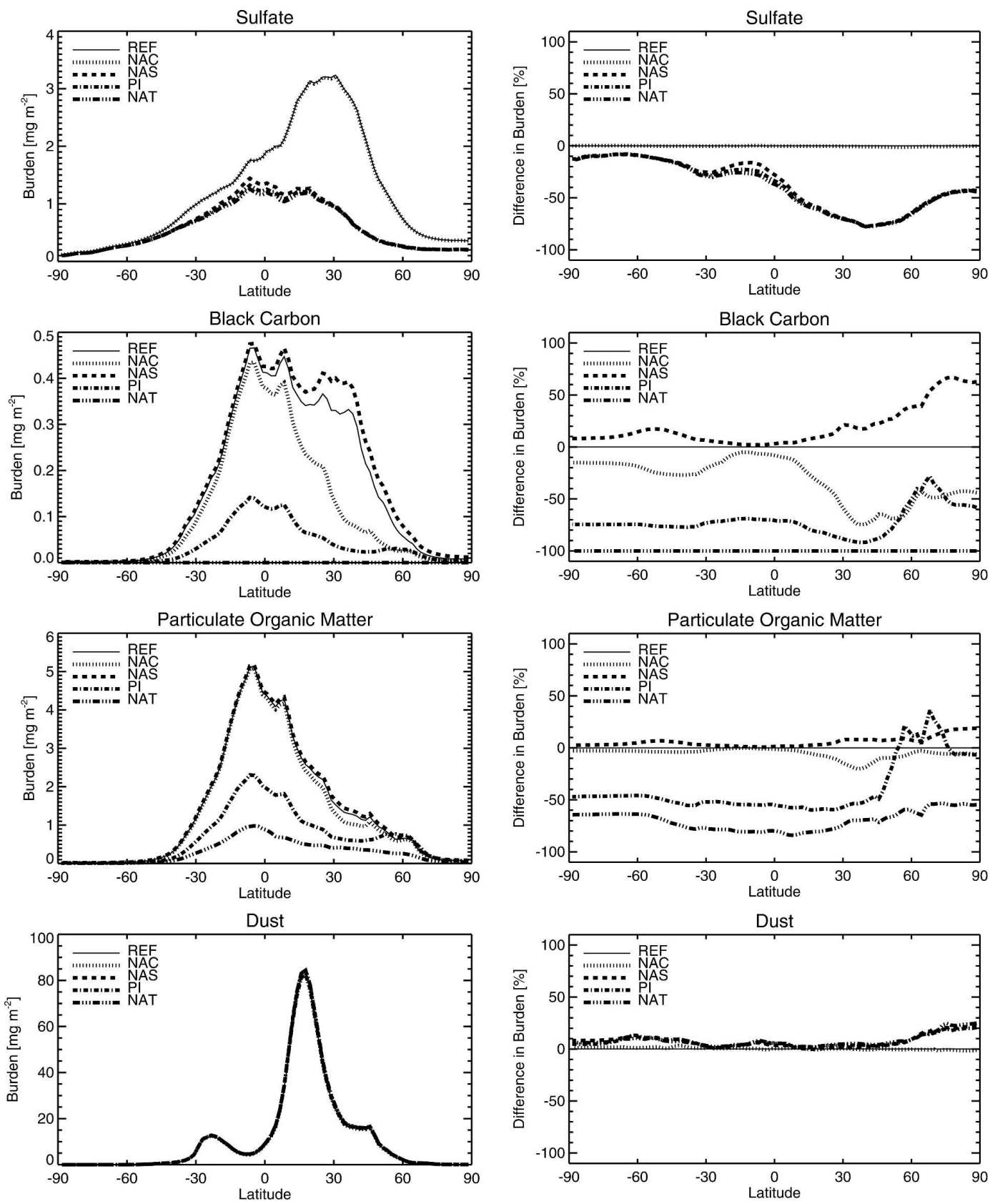

FIG. 2. Annual zonal-mean aerosol column burdens in $[\mathrm{Tg}]$ and $[\mathrm{Tg}(\mathrm{S})]$ and the percent changes with respect to REF for NAT, PI, NAS, and NAC.

Lifetime and burden of the natural dust cycle are less sensitive to changes in anthropogenic emissions. Global annual-mean dust burdens increase by $3.4 \%, 2.9 \%$, and $1.5 \%$ for the NAT, PI, and NAS scenarios, respectively. However, the zonal distribution of the burden changes for the NAS, NAT, and PI scenarios indicates that the zonal-mean dust burden in remote areas is enhanced by up to $20 \%$, and also the lifetime is slightly enhanced.
Regionally, the increase in dust burden exceeds $40 \%$ for the NAT scenario (not shown). The increased aging time is consistent with a decrease in microphysical aging.

In summary, the response of aerosol mass to anthropogenic emission changes shows significant nonlinearities manifested as changes in the aerosol lifetime. The induced changes in the annual zonal-mean mass bur- 
dens are type and source specific. A clear coherence among the aerosol cycles, caused by microphysical coupling, is evident.

\section{b. Response of aerosol numbers}

In the preceding paragraph we showed that the mass response of the global aerosol system to changes in emissions shows significant nonlinearities and that there is a microphysical coupling of the aerosol cycles. As aerosol mass and numbers are interdependent, a nonlinear response of aerosol numbers to changes in emissions is to be expected. In this paragraph we analyze the linearity of the changes of the aerosol numbers with respect to the (demonstrable nonlinear) changes in the mass distribution.

The annual zonal-mean distribution of the aerosol number column burdens of each mode and their percent changes for the different scenarios are depicted in Fig. 3. Nucleation mode and Aitken mode soluble number burdens are dominated by nucleation of gas-phase sulfuric acid. Therefore, their decrease in the NAS, PI, and NAT scenarios is most pronounced in the Northern Hemisphere, where most of the emission reductions occur compared to REF. It is interesting to note, that although the total source of gas-phase sulfuric acid decreases from the REF scenario to the NAS scenario by $-13.8 \mathrm{Tg}(\mathrm{S}) \mathrm{yr}^{-1}(-49.5 \%)$, the global mean number burden of the soluble nucleation, Aitken, and accumulation modes decrease by $-7.4 \%,-16.9 \%$, and $-21.1 \%$, respectively. This is an indication that the secondary production processes are saturated so that the nucleation mode number burdens are less than proportionally affected by changes in the sulfuric emissions. The global mean accumulation mode soluble number burden decreases from the REF scenario by $-4.6 \%$ for the NAC, by $-42.3 \%$ for the PI, and by $-56.7 \%$ for the NAT scenario. As discernible in Fig. 3, the strongest decrease occurs in the Northern Hemisphere, where the anthropogenic contribution is large and the decrease of the emissions is most pronounced. Only the reduction of tropical biomass burning in the PI and NAT scenarios causes a distinct decrease of Southern Hemispheric accumulation mode number burdens. The effect of microphysical aging is most prominently cognizable in the changes of the insoluble Aitken mode number concentrations. With the decrease of the sulfate emissions in the NAS scenario, the insoluble Aitken mode number burdens increase by up to $400 \%$ with a maximum centered around $35^{\circ} \mathrm{N}$. The analog of this is that the number burdens of the insoluble accumulation and coarse modes increase with decreasing anthropogenic emissions in the NAS, PI, and NAT scenarios. Correspondingly, the peak of the soluble coarse mode number burden around $15^{\circ} \mathrm{N}$, attributable to aged dust particles, is decreased. The reduction in primary particle emission in the NAC scenario decreases the insoluble Aitken mode number burden between $15^{\circ}$ and $70^{\circ} \mathrm{N}$ by up to $-80 \%$.

For our analysis of the linearity, we focus on the soluble accumulation mode as it dominates the anthropogenic contribution to optical depth and cloud condensation nuclei and is therefore of fundamental importance for estimates of direct and indirect aerosol effects. Let $\lambda$ be the ratio of the normalized change in vertically integrated aerosol numbers $\Delta \mathcal{X}$ to the normalized change in vertically integrated aerosol mass $\Delta \mathcal{M}$ :

$$
\lambda=\frac{\Delta \mathcal{X}}{\Delta \mathcal{M}} \equiv \frac{\left(N^{\mathrm{REF}}-N\right) / N^{\mathrm{REF}}}{\left(M^{\mathrm{REF}}-M\right) / M^{\mathrm{REF}}} .
$$

Hereby, $N$ and $M$ are the number and mass burden of the respective scenario and $N^{\mathrm{REF}}$ and $M^{\mathrm{REF}}$ are the number and mass burdens of the reference scenario. We limit our analysis to cases of $\Delta \mathcal{M}>1 \%$, as $\lambda$ can become ill defined for $\Delta \mathscr{M} \rightarrow 0$. Values of $\lambda \approx 1$ indicate a linear change of aerosol mass and numbers. Values of $0<\lambda<1$ indicate that the relative change in aerosol numbers is less than the change in the aerosol mass compared to the reference scenario. For $\lambda>1$ the relative change in aerosol numbers is larger than the change in aerosol mass compared to the reference scenario. Values of $\lambda<0$ indicate anticorrelated changes of mass and numbers.

The annual-mean distributions of $\lambda$ for the soluble accumulation mode for the NAC, NAS, NA, and NAT scenarios are displayed in Figs. 4a-d.

For the NAC scenario, $\lambda$ is larger than one in most regions with significant changes in the mass burden. This indicates that the changes in the number burden exceed the changes in the mass burden. That is, the anthropogenic carbonaceous emissions, with a large primary contribution, contribute disproportionately to the number of accumulation mode particles. In the continental plumes over the Northern Hemispheric oceans $\lambda$ decreases with increasing distance from the sources, reaching values of $\lambda \approx 1$. In high northern latitudes $\lambda$ shows values of $0<\lambda<1$. A possible explanation is that the increased microphysical sink in the source regions from the NAC to the REF scenario, introduced by the primary emissions, subsequently reduces the availability of sulfate for secondary particle formation in remote regions.

In contrast, for the NAS scenario $\lambda$ is smaller than one close to the source regions and larger than one in the remote ocean regions. This indicates that the rela- 

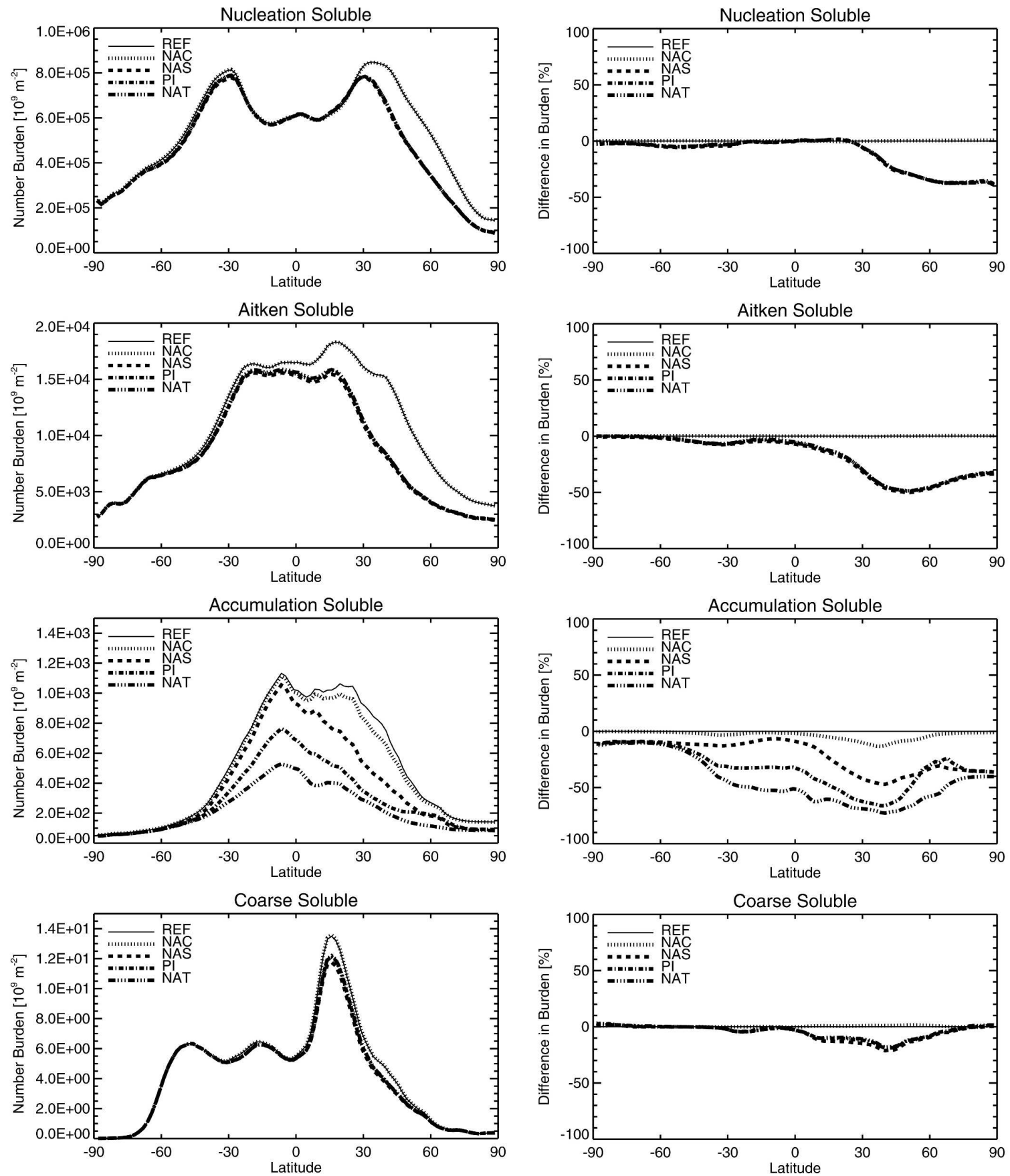

FIG. 3. Annual zonal-mean aerosol number column burdens [in $10^{9} \mathrm{~m}^{-2}$ ] for each mode and the percent changes with respect to REF for NAT, PI, NAS, and NAC.

tive changes in the number burden is less than the changes in the mass burden close to the source and vice versa in remote regions and can be explained as follows. In the presence of sufficient aerosols, as in the anthropogenic source regions, an increase of the sulfate source from $34.6 \mathrm{Tg}(\mathrm{S}) \mathrm{yr}^{-1}$ in NAS to $76.1 \mathrm{Tg}(\mathrm{S}) \mathrm{yr}^{-1}$ in REF does not linearly increase the number of accumulation mode particles. A fraction of sulfate condenses on preexisting particles and smaller particles preferentially coagulate with the available large particles, less than proportionally increasing the number of accumulation mode particles. (In the reference run, glo- 

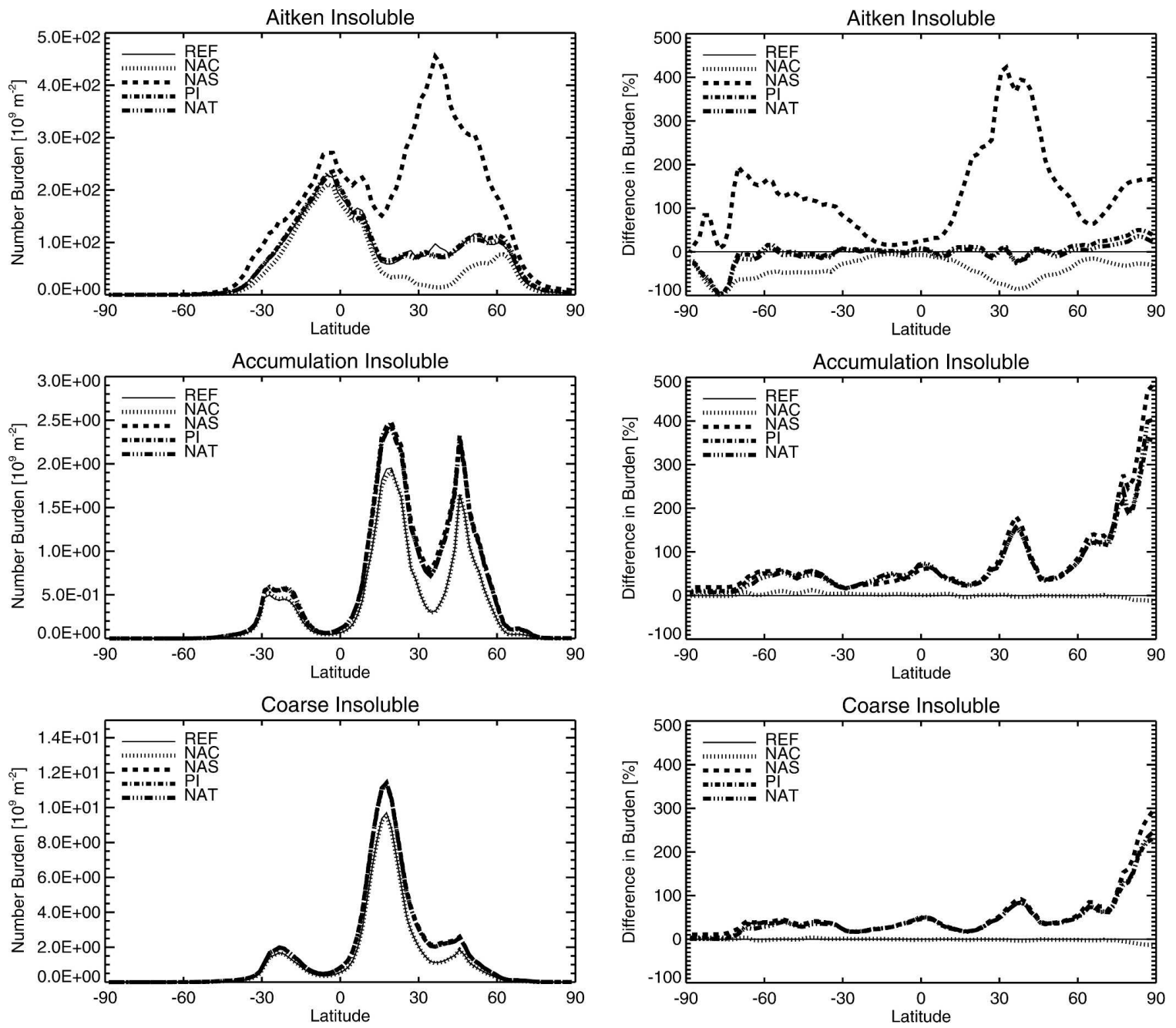

FIG. 3. (Continued)

bally $36.4 \%$ of the total sulfate source condensate on preexisting aerosol particles.) In the remote regions, characterized by a lower available aerosol surface area and low primary sources, secondary particle formation accounts for a large fraction of the total accumulation mode number burden (not shown). Therefore, in these regions the increase of the sulfate source from NAS to REF disproportionately enhances the formation of accumulation mode particles via enhanced nucleation and growth processes.

The combined NA scenario shows a similar distribution of $\lambda$ as the NAS scenario, as the aerosol mass source reductions in NAS are by more than one order of magnitude larger than in NAC (cf. Table 4). However, in the source regions the small values of $\lambda<1$ in NAS are partly compensated for by the contribution of the primary carbonaceous emissions with $\lambda>1$ in NAC.
It is interesting to note that in the natural NAT scenario the main patterns of nonlinearity still resemble the effect of the sulfuric emissions in the NAS scenario. However, the accumulation mode soluble particle numbers increase closer to linearity with the mass over large parts of the continents, indicated by values of $\lambda \approx 1$. One possible explanation is that the emissions of primary particles and of secondary particle precursors balance each other from natural to present-day conditions resulting in the quasi-linear behavior over large parts of the continents. Over most parts of the remote oceanic regions, values of $\lambda>1$ indicate a disproportionate increase of the aerosol numbers compared to aerosol mass.

In summary, the analysis of the response of aerosol number burdens to emission changes reveals distinct nonlinearities. Strongest nonlinearities occur in the vicinity of the aerosol source regions. Primary aerosols 
a)
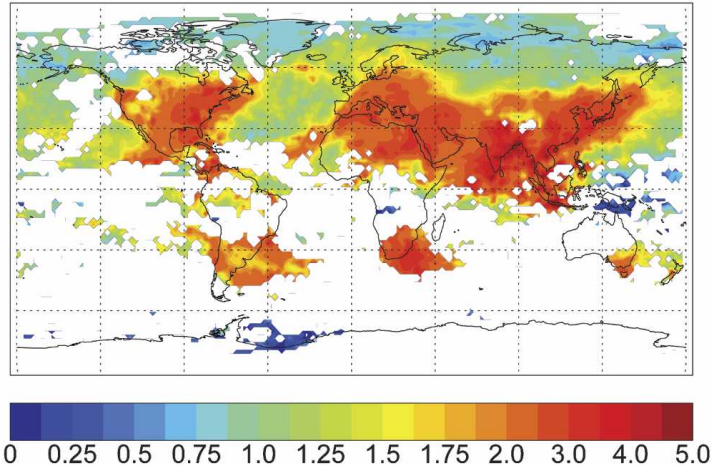

c)
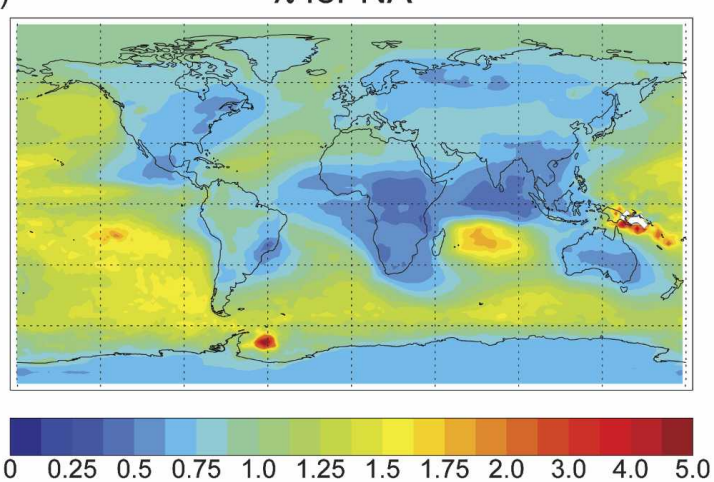

e)

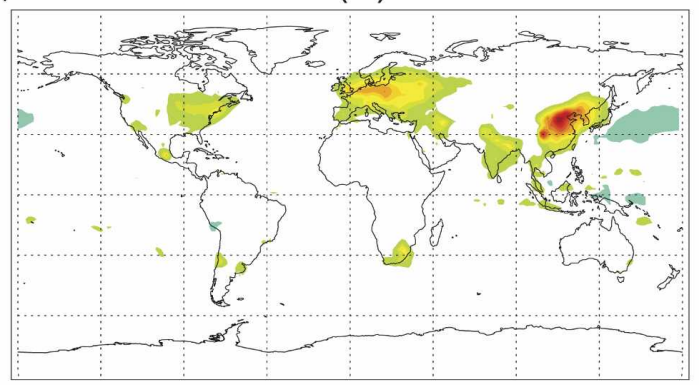

$-30 \%-25 \%-20 \%-15 \%-10 \%-5 \% \quad 0 \quad 5 \% \quad 10 \% \quad 15 \% \quad 20 \% \quad 25 \% \quad 30 \%$ b)

$\lambda$ for NAS
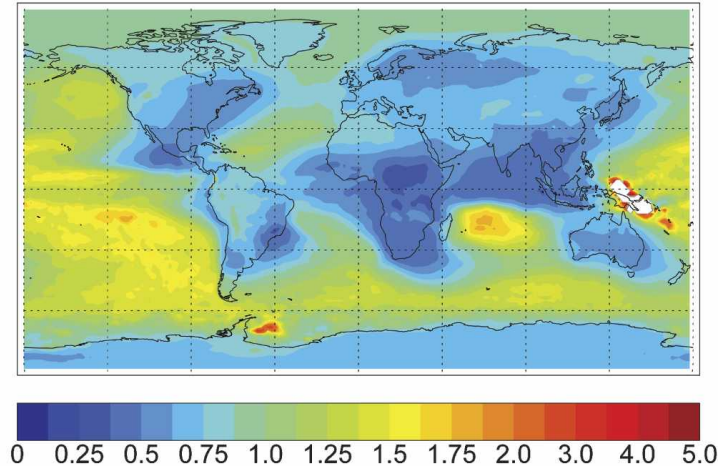

d)
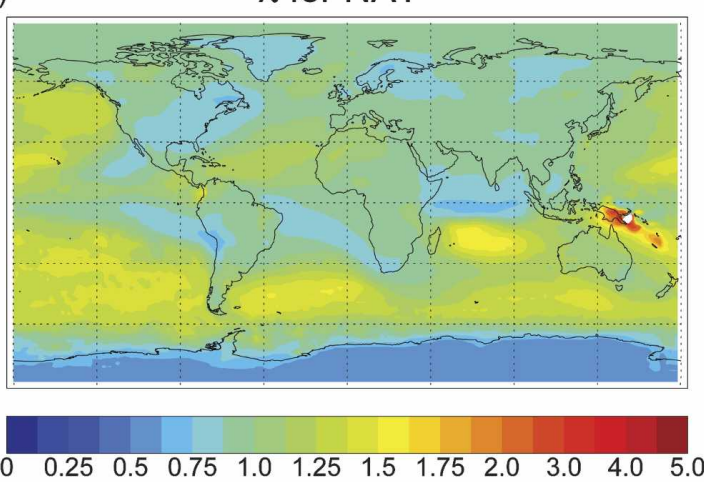

f)

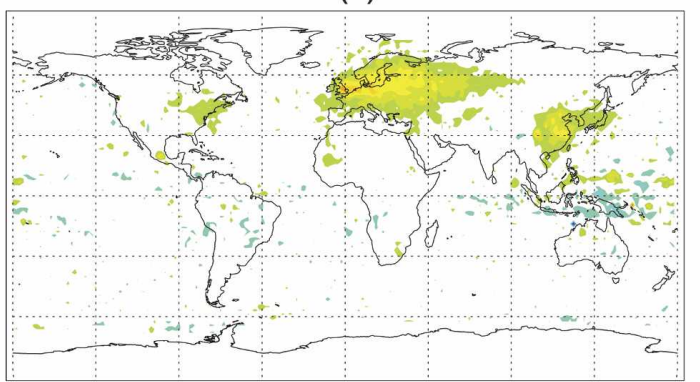

$-30 \%-25 \%-20 \%-15 \%-10 \%-5 \% \quad 0 \quad 5 \% \quad 10 \% \quad 15 \% \quad 20 \% \quad 25 \% \quad 30 \%$

FIG. 4. Annual-mean nonlinearity factor $\lambda$ for the soluble accumulation mode as defined in Eq. (1) for the (a) NAC, (b) NAS, (c) NA, and (d) NAT scenarios. Annual-mean additivity factor $\alpha$ as defined in Eq. (2) for (e) the accumulation mode soluble number burden $N$ and (f) the aerosol optical depth $\tau$ at $550 \mathrm{~nm}$, for the NAS and NAC scenarios compared to the NA scenario. Regions of $\lambda$ with $\Delta \mathscr{M}<1 \%$ are masked out in (a)-(d). Regions of $\alpha$ with $\tau^{\mathrm{REF}}<0.05$ are masked out in (f).

contribute preferentially to the formation of accumulation mode particles. Increasing emissions of secondary aerosol precursors less than proportionally increase the accumulation mode aerosol numbers close to the sources and disproportionately increase the accumulation mode aerosol numbers in the remote regions. These effects can potentially cancel out in the case of concurrent emission changes.

\section{c. Response of aerosol optical depth}

We demonstrated that aerosol mass and aerosol number respond nonlinearly to changes in aerosol emissions. The optical depth in turn is nonlinearly coupled to the aerosol numbers and mass via the size distribution, composition, and mixing state. Therefore, a nonlinear response of the aerosol optical thickness to 

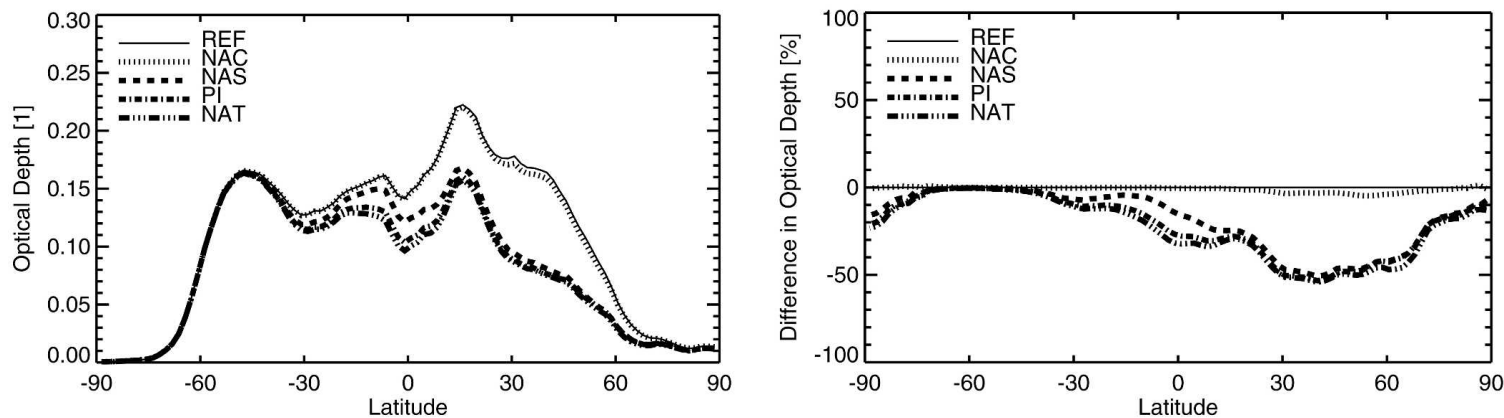

FIG. 5. Annual zonal-mean aerosol optical depth at a wavelength of $550 \mathrm{~nm}$ and the percent changes with respect to REF for NAT, PI, NAS, and NAC.

emission changes is to be expected and is not further investigated. The annual zonal-mean distribution of the aerosol optical depth $(\tau)$ and the percent changes for the different scenarios are depicted in Fig. 5. The strongest effect of anthropogenic emissions on $\tau$ can be attributed to the sulfuric emission from fossil fuels, industry, and biofuels. In the NAS scenario, zonal-mean optical depths between $20^{\circ}$ and $70^{\circ} \mathrm{N}$ decrease by up to $-50 \%$. Regionally, close to the North American and Asian anthropogenic sulfuric source regions, the reduction reaches more than $-80 \%$ (not shown).

The effect of the reduction of carbonaceous emissions in the NAC scenario on the annual zonal-mean of $\tau$ is less than $-5 \%$. Regionally, close to the European and Asian source regions of carbonaceous aerosols from fossil fuels and industry the reductions reach around $-15 \%$ (not shown). The maximal zonal-mean difference between the NAS and PI and between the NAS and NAT scenarios, attributable to the reduction in biomass burning, is discernible in the Tropics, reaching $-15 \%$ and $-20 \%$ at the equator, respectively. The influence of anthropogenic emission on the zonal-mean aerosol optical thickness in the extratropical Southern Hemisphere is small.

\section{d. Analysis of the additivity}

In the development of emission strategies for aerosol and their precursors, it is of fundamental importance to forecast the total effect of a number of concurrent emission changes. In bulk aerosol models, traditionally used for the assessment of aerosol effects, the change in the aerosol system from a simulation with emission changes for several compounds is the sum of changes of single simulations in each of which the emission changes were introduced. That is, the response of the aerosol system is constrained to the concept of additivity. This is the underlying principle of the forcing concept applied for the analysis of the radiative effects of aerosols in the Houghton et al. (2001) assessment report.

Here, we analyze the additivity of the microphysically coupled aerosol system, taking into account the coherence of aerosol cycles demonstrated in sections $3 \mathrm{a}$ and $3 \mathrm{~b}$. We compare the results from the NAC and NAS scenarios to the NA scenario in which the emission reductions from both scenarios are combined. Let $\alpha$ be a measure of the additivity for the quantity $X$ defined as

$$
\alpha(X)=\frac{\Delta X^{\mathrm{NA}}-\Delta X^{\mathrm{NAS}}-\Delta X^{\mathrm{NAC}}}{X^{\mathrm{REF}}} .
$$

Hereby is $\Delta X^{i}=X^{i}-X^{\mathrm{REF}}$ for the scenarios $i \in$ (NA, NAS, NAC). If the aerosol system follows additivity, $\alpha$ is zero as $\Delta X^{N A}=\Delta X^{N A S}+\Delta X^{N A C}$.

To isolate the effect of microphysical interactions owing to the coemission of the sulfate and carbonaceous sources, we can rewrite Eq. (2) to

$$
\alpha(X)=\frac{\left(X^{\mathrm{REF}}-X^{\mathrm{NA}}\right)-\left[\left(X^{\mathrm{NAS}}-X^{\mathrm{NA}}\right)+\left(X^{\mathrm{NAC}}-X^{\mathrm{NA}}\right)\right]}{X^{\mathrm{REF}}} .
$$

The first term in the numerator is the change of $X$, conceptually starting from an atmosphere without the sulfate and carbonaceous aerosol sources (NA), due to the coemission of sulfate and carbonaceous sources. The latter two terms are the changes of $X$ due to the individual emissions of sulfate and carbonaceous sources. Thus, positive values of $\alpha$ indicate that the change of $X$ is larger when sulfate and carbonaceous sources are coemitted, as $X^{i}-X^{\mathrm{NA}}$ is positive for the quantities of interest. On the contrary, negative values 
of $\alpha$ indicate that the sum of changes of $X$ due to the individual emissions is smaller than for the case of coemission.

The global distribution of $\alpha$ for the accumulation mode soluble number burden $(N)$ is shown in Fig. 4e. Close to the anthropogenic source regions, $\alpha(N)$ shows a positive deviation from additivity, reaching up to $+30 \%$. That is, the coemission of sulfate and carbonaceous sources increases $N$ more efficiently than the sum of the increases of $N$ due to the individual emission of sulfate and carbonaceous sources. This is indicative of the synergy of the coemitted aerosol components to reach the accumulation mode size range. With the coemission of primary carbonaceous seeds, the condensation of gas-phase sulfuric acid is distributed over a larger number of seeds that grow to the radiatively important accumulation mode size range. In the absence of the carbonaceous seeds and their large surface area, more gas-phase sulfuric acid condenses on the present accumulation mode particles so that particle growth on the expense of the formation of new accumulation mode particles dominates in the polluted regions. On the contrary, in the plume downwind of the main Asiatic source regions, small negative values of $\alpha(N)$ prevail, attributable to the effect of increased microphysical aging and subsequent enhanced removal for the case of aerosol coemissions.

The corresponding positive deviations from additivity, reaching up to $+15 \%$, are also evident in the distribution of $\alpha(\tau)$ for the aerosol optical depth, displayed in Fig. 4f. This can be attributed to the fact that the aerosol optical depth over the anthropogenic source regions is dominated by the contribution of aerosols from the accumulation mode soluble. Therefore, the enhancement of the formation of $N$ owing to coemission results in a corresponding behavior of the aerosol optical depth in the polluted regions.

\section{Summary and conclusions}

In a series of simulations with the ECHAM5-HAM aerosol-climate model, we analyzed the response of the global aerosol system to changes in anthropogenic emissions. In the microphysical aerosol module HAM, sink processes and radiative properties are parameterized in terms of prognosed size distribution, mixing state, and composition, establishing degrees of freedom for nonlinear responses of the aerosol system. The large-scale meteorology in each simulation was constrained to year-2000 ERA-40 data. From a reference simulation with year-2000 emissions, we progressively reduced the emission of specific anthropogenic aerosols and aerosol precursors. We consider a scenario without
$\mathrm{SO}_{2}$ emissions from fossil fuel use and industry and biofuels (NAS), a scenario without BC and POM emissions from fossil fuel use and industry (NAC), and a combined scenario without $\mathrm{SO}_{2}$ emissions from fossil fuel use, industry, and biofuels and without $\mathrm{BC}$ and POM emissions from fossil fuel use and industry (NA). Additionally, we consider a preindustrial scenario with emissions for the year 1750 (PI) and a scenario with solely natural emissions (NAT).

The analysis of the response of the global aerosol system to the emission changes reveals significant nonlinearities. Global annual-mean mass burdens respond nonlinearly to the induced emission changes, manifested in alterations of the aerosol lifetimes. From preindustrial to present-day aerosol emissions, the sulfate lifetime decreased by $-10.2 \%$, the black carbon lifetime decreased by $-22.6 \%$, the particulate organic matter lifetime increased by $10.6 \%$, and the mineral dust lifetime decreased by $-1.9 \%$. The alterations in aerosol lifetime cannot unambiguously attributed to microphysical processes, as lifetimes are also affected by geographical shifts of the dominant aerosol source regions. The natural sea salt cycle is unaffected by the anthropogenic emissions and shows only negligible variations.

The impact of specific anthropogenic emission reductions on aerosol cycles with unaltered emissions, manifested in increased lifetimes, column burdens, and microphysical aging times, is a clear indicator for the coherence of the aerosol cycles. In the scenario without anthropogenic sulfate emissions, annual global-mean lifetimes of black carbon, particulate organic matter, and dust increase by $8.9 \%, 2.5 \%$, and $1.5 \%$, respectively; microphysical aging times increase by $164 \%$, $84 \%$, and $66 \%$, respectively; and annual zonal-mean column burdens in high northern latitudes increase by up to $70 \%, 20 \%$, and $20 \%$, respectively.

A linearity analysis of the changes of accumulation mode soluble number burdens with respect to the corresponding changes in mass burden indicated substantial nonlinearities. Comparing the NAC scenario with the reference scenario, anthropogenic carbonaceous emissions disproportionately contribute to the accumulation mode number burden, particularly close to the source regions. In contrast, anthropogenic sulfuric emissions less than proportionally contribute to the accumulation mode number burden close to the source regions and disproportionately contribute in remote regions. From natural to present-day conditions, the increase of both carbonaceous and sulfuric emissions partly offset these nonlinearities. However, the main patterns of nonlinearity still resemble the effect of the sulfuric emissions, though with reduced amplitude.

We analyzed the additivity of the aerosol system by 
comparing the sum of the changes from the NAS and NAC scenarios, with respect to the reference scenario, with the change from the NA scenario in which the emission changes of NAS and NAC are combined. For the accumulation mode soluble number burden and the aerosol optical depth, considerable deviations from additivity occur close to the main anthropogenic source regions where the aerosol concentrations are highest. There, the enhanced microphysical interactions for the case of coemission of anthropogenic carbonaceous and sulfuric emissions result in an up to $30 \%$ increase of the accumulation mode number burden when compared with the sum of the changes from the separate emissions. With the coemission of primary carbonaceous seeds, the condensation of gas-phase sulfuric acid and coagulation grow a larger number of particles to the radiatively important accumulation mode size range. On the contrary, the enhanced microphysical aging for the case of the coemission enhances the wet removal and therefore reduces the number burden in the export regions, causing deviations from additivity of up to $8 \%$. The resulting aerosol optical depth reflects the behavior in the polluted regions with local deviations from additivity up to $15 \%$.

The demonstrated nonlinearities, the coherence among the different aerosol cycles, and the deviations from additivity challenge the bulk approach established in global aerosol models. Bulk models do not provide the degrees of freedom for these effects to be included. In addition, our results suggest that the separate perception of the different aerosol components and their precursors can lead to nonnegligible errors in estimates of the aerosol radiative effects. Traditionally, the radiative effects of specific aerosol components have been derived separately. Our results, in contrast, suggest that estimates of the contribution of specific aerosol components to the radiative effects require simulations with the fully coupled aerosol system but with the component of interest omitted.

There are manifold potential impacts of our results on the global climate system. We showed that changes in anthropogenic emissions affect the microphysical aging capacity of the atmosphere, which in turn affects the aerosol lifetimes, global distributions, and radiative effects. The demonstrated increase in the transfer of insoluble to soluble particles due to anthropogenic emissions potentially increases the number of $\mathrm{CCN}$ affecting the indirect aerosol effects. The exposed deviations from additivity challenge the concept of radiative forcing applied in Houghton et al. (2001) for the assessment of the aerosol radiative effects. The anthropogenic modulation of the high-latitude aerosol concentrations and deposition rates-also of natural components-has consequences for the interpretation of ice core data. It suggests that the aerosol concentration in ice cores might not be such a direct measure of the atmospheric aerosol load as previously assumed (e.g., Kohfeld and Harrison 2001). For example, the omission of anthropogenic sulfur emissions increases the high-latitude dust deposition by up to $20 \%$, while the global dust mass burden is only increased by $1.5 \%$. The strong increase of black carbon at high northern latitudes due to the omission of anthropogenic sulfuric emissions should be emphasized. This region is prone to changes in the surface albedo and ice feedbacks, and it has been proposed that black carbon deposition on snow and ice exerts a significant positive climate forcing (Hansen and Nazarenko 2004). Enhanced deposition of black carbon due to mitigation of sulfuric aerosol precursors could amplify this effect. This example emphasizes the need for integrated emission strategies for aerosols and their precursors making up the cross-connections of the global aerosol cycles.

Although the ECHAM5-HAM aerosol-climate model used is advanced in terms of the aerosol representation and microphysical detail compared to most previous global models suitable for long-term simulations, large uncertainties remain. Important aerosol components such as nitrate as well as important processes such as the treatment of semivolatile species are neglected. In particular the fact that secondary organic aerosols are substituted by a primary approach constitutes an underestimation of the amount of condensable material and therefore of the coupling of the aerosol cycles. On the contrary, the neglect of natural condensable vapors potentially exaggerates the effect of the anthropogenic sulfuric emissions on the natural aerosol cycles. Here we focus on the nonlinear response of the microphysical aerosol system to emission changes under constrained conditions. Additional feedbacks and nonlinearities are to be expected when feedbacks to the meteorology, to the atmospheric chemistry, and to the natural biogeochemical cycles are taken into account. In particular the scavenging efficiencies play an important role for the microphysical coupling of the aerosol cycles. For example, an (unphysical) assumption of identical scavenging parameters for the insoluble and soluble modes would reduce the effect of soluble on insoluble aerosol components. On the contrary, the assumption of zero wettability of the insoluble modes, as has been used in previous studies (e.g., Cooke et al. 1999), would further enhance this effect. Our choice of reduced but nonzero scavenging parameters for the insoluble modes accounts for unresolvable subgrid-scale aging processes and can be seen as a conservative estimate. 
Large uncertainties are also associated with the nucleation of gas-phase aerosol precursors, subgridscale processes, the gridbox average mixing state of emissions, operator splitting procedures, and the accommodation coefficients for the condensation of gases on preexisting aerosols.

However, while these uncertainties may individually influence the magnitude of the simulated effects, we have no reasons to assume that taken together they affect the key mechanisms identified in this study, nor do they affect the main conclusions. It emerges that the global aerosol system is characterized by inherent nonlinearities that cannot be accounted for in the traditional bulk modeling approach. Further studies with advanced global aerosol models are required to reduce the associated uncertainties and to constrain the impacts on the aerosol radiative effects.

Acknowledgments. This work was supported by the German climate research program DEKLIM. Review comments by two anonymous reviewers as well as by Stefan Kinne, Erich Roeckner, and Martin Schultz greatly improved this manuscript.

\section{REFERENCES}

Adams, P. J., and J. H. Seinfeld, 2002: Predicting global aerosol size distributions in general circulation models. J. Geophys. Res., 107, 4370, doi:10.1029/2001JD001010.

Albrecht, B. A., 1989: Aerosols, cloud microphysics, and fractional cloudiness. Science, 245, 1227-1230.

Andreae, M., and P. Crutzen, 1997: Atmospheric aerosols: Biogeochemical sources and role in atmospheric chemistry. Science, 276, 1052-1058.

Ångström, A., 1962: Atmospheric turbidity, global illumination and planetary albedo of the earth. Tellus, 14, 435-450.

Bates, T. S., B. J. Huebert, J. L. Gras, F. B. Griffiths, and P. A. Durkee, 1998: International global atmospheric chemistry (IGAC) project's first aerosol characterisation experiment (ACE 1): Overview. J. Geophys. Res., 103, 16 297-16 318.

Charlson, R., J. Lovelock, M. Andreae, and S. Warren, 1987: Oceanic phytoplankton, atmospheric sulphur, cloud albedo and climate. Nature, 326, 655-661.

Chin, M., R. B. Rood, S. Lin, J. Müller, and A. M. Thompson, 2000: Atmospheric sulfur cycle simulated in the global model GOCART: Model description and global properties. J. Geophys. Res., 105, 24 671-24 688.

—_ and Coauthors, 2002: Tropospheric aerosol optical thickness from the GOCART model and comparisons with satellite and sun photometer measurements. J. Atmos. Sci., 59, 461483.

Chuang, C., and J. Penner, 1995: Effects of anthropogenic sulfate on cloud drop nucleation and optical-properties. Tellus, 47B, $566-577$.

— — - K. Taylor, A. Grossman, and J. Walton, 1997: An assessment of the radiative effects of anthropogenic sulfate. $J$. Geophys. Res., 102, 3761-3778.

Cooke, W. F., and J. J. N. Wilson, 1996: A global black carbon aerosol model. J. Geophys. Res., 101, 19 395-19 410.
C. Liousse, H. Cachier, and J. Feichter, 1999: Construction of a $1^{\circ} \times 1^{\circ}$ fossil fuel emission data set for carbonaceous aerosol and implementation and radiative impact in the ECHAM4 model. J. Geophys. Res., 104, 22 137-22 162.

Crutzen, P., 1996: The role of particulate matter in ozone photochemistry. Nucleation of Atmospheric Aerosols, M. Kulmala and P. E. Wagner, Eds., Elsevier, 268-270.

Dentener, F., and Coauthors, 2006: Emissions of primary aerosol and precursor gases in the years 2000 and 1750, prescribed data-sets for AeroCom. Atmos. Chem. Phys. Discuss., 6, 2703-2763.

Dockery, D. W., A. C. Pope, X. Xu, J. D. Spengler, J. H. Ware, M. E. Fay, B. G. Ferris, and F. E. Speizer, 1993: An association between air pollution and mortality in six U.S. cities. New England J. Med., 329, 1753-1759.

EC, 1999: Directive 199/30ec relating to limit values for sulphur dioxide, oxides of nitrogen, particulate matter and lead in air. J. Eur. Commun., L163, 41-60.

Emmons, L. K., and Coauthors, 2003: Budget of tropospheric ozone during TOPSE from two chemical transport models. $J$. Geophys. Res., 108, 8372, doi:10.1029/2002JD002665.

Feichter, J., E. Kjellström, H. Rodhe, F. Dentener, J. Lelieveld, and G.-J. Roelofs, 1996: Simulation of the tropospheric sulfur cycle in a global climate model. Atmos. Environ., 30, 16931707.

—, E. Roeckner, U. Lohmann, and B. Liepert, 2004: Nonlinear aspects of the climate response to greenhouse gas and aerosol forcing. J. Climate, 17, 2384-2398.

Fouquart, Y., and B. Bonnel, 1980: Computations of solar heating of the earth's atmosphere: A new parameterization. Beitr. Phys. Atmos., 53, 35-62.

Ghan, S. J., R. C. Easter, J. Hudson, and F.-M. Brèon, 2001a: Evaluation of aerosol indirect radiative forcing in MIRAGE. J. Geophys. Res., 106, 5317-5334.

—, N. Laulainen, R. Easter, R. Wagener, S. Nemesure, E. Chapman, and Y. Z. R. Leung, 2001b: Evaluation of aerosol direct radiative forcing in MIRAGE. J. Geophys. Res., 106, 5295-5316.

Ginoux, P., M. Chin, I. Tegen, J. M. Prospero, B. Holben, O. Dubovik, and S.-J. Lin, 2001: Sources and distributions of dust aerosols simulated with the GOCART model. J. Geophys. Res., 106, 20 255-20 274.

Graßl, H., 1975: Albedo reduction and radiative heating of clouds by absorbing aerosol particles. Contrib. Atmos. Phys., 48, 199-210.

Graf, H.-F., J. Feichter, and B. Langmann, 1997: Volcanic sulfur emissions: Estimates of source strength and its contribution to the global sulfate distribution. J. Geophys. Res., 102, $10727-10738$.

Guelle, W., M. Schulz, Y. Balkanski, and F. Dentener, 2001: Influence of the source formulation on modeling the atmospheric global distribution of sea salt aerosol. J. Geophys. Res., 106, 27 509-27 524.

Hansen, J. E., and L. Nazarenko, 2004: Soot climate forcing via snow and ice albedos. Proc. Natl. Acad. Sci. USA, 101, doi:10.1073/pnas.2237157100.

- M. Sato, and R. Ruedy, 1997: Radiative forcing and climate response. J. Geophys. Res., 102, 6831-6864.

Haywood, J. M., D. L. Roberts, A. Slingo, J. M. Edwards, and K. P. Shine, 1997: General circulation model calculations of the direct radiative forcing by anthropogenic sulfate and fossil-fuel soot aerosol. J. Climate, 10, 1562-1577.

Heintzenberg, J., and Coauthors, 2003: Tropospheric aerosols. At- 
mospheric Chemistry in a Changing World: An Integration and Synthesis of a Decade of Tropospheric Chemistry Research, G. P. Brasseur, R. G. Prinn, and A. P. Pszenny, Eds., Global Change-The IGBP Series, Springer, 125-156.

Houghton, J. T., Y. Ding, D. J. Griggs, M. Noguer, P. J. van der Linden, X. Dai, K. Maskell, and C. A. Johnson, Eds., 2001: Climate Change 2001: The Scientific Basis. Cambridge University Press, $881 \mathrm{pp}$.

Jeuken, A. B. M., P. C. Siegmund, L. C. Heijboer, J. Feichter, and L. Bengtsson, 1996: On the potential of assimilating meteorological analyses in a global climate model for the purpose of model validation. J. Geophys. Res., 101, 16 939-16950.

Johnson, K., R. Gordon, and K. Coale, 1997: What controls dissolved iron concentrations in the world ocean? Mar. Chem., 57, 137-161.

Kettle, A., and M. Andreae, 2000: Flux of the dimethylsulfide from the oceans: A comparison of updated data sets and flux models. J. Geophys. Res., 105, 26 793-26 808.

Kinne, S., and Coauthors, 2005: An AEROCOM initial assessment-Optical properties in aerosol component modules of global models. Atmos. Chem. Phys. Discuss., 5, 8285-8330.

Kohfeld, K. E., and S. P. Harrison, 2001: DIRTMAP: The geological record of dust. Earth-Sci. Rev., 54, 81-114.

Langner, J., and H. Rhode, 1991: A global three-dimensional model of the global sulfur cycle. J. Atmos. Chem., 13, 225263.

Liepert, B. G., J. Feichter, U. Lohmann, and E. Roeckner, 2004: Can aerosols spin down the water cycle in a warmer and moister world? Geophys. Res. Lett., 31, L06207, doi:10.1029/ 2003 GL019060.

Lin, S. J., and R. B. Rood, 1996: Multidimensional flux form semiLagrangian transport. Mon. Wea. Rev., 124, 2046-2068.

Liousse, C., J. E. Penner, C. Chuang, J. J. Walton, H. Eddleman, and H. Cachier, 1996: A global three-dimensional model study of carbonaceous aerosols. J. Geophys. Res., 101, 19 411-19 432

Lippmann, M., 2000: Association of particulate matter components with daily mortality and morbidity in urban populations. HEI Res. Rep. 95, Health Effects Institute, Boston, MA, 84 pp. [Available online at http://www.healtheffects.org.]

Lohmann, U., 2002: A glaciation indirect aerosol effect caused by soot aerosols. Geophys. Res. Lett., 29, 1052, doi:10.1029/ 2001 GL014357.

— , and E. Roeckner, 1996: Design and performance of a new cloud microphysics scheme developed for the ECHAM4 general circulation model. Climate Dyn., 12, 557-572.

— J. Jeichter, C. C. Chuang, and J. E. Penner, 1999: Predicting the number of cloud droplets in the ECHAM-GCM. J. Geophys. Res., 104, 9169-9198.

Marsland, S. J., H. Haak, J. H. Jungclaus, M. Latif, and F. Röske, 2003: The Max-Planck-Institute global ocean/sea ice model with orthogonal curvilinear coordinates. Ocean Modell., 5, 91-127.

Mayol-Bracero, M.-O., and Coauthors, 2002: Water-soluble organic compounds in biomass burning aerosols over Amazonia 2. Apportionment of the chemical composition and importance of the polyacidic fraction. J. Geophys. Res., 107, 8091, doi:10.1029/2001JD000522.

McCormic, R. A., and J. H. Ludwig, 1967: Climate modifications by atmospheric aerosols. Science, 156, 1358-1359.

Mlawer, E. J., S. J. Taubman, P. D. Brown, M. J. Iacono, and S. A. Clough, 1997: Radiative transfer for inhomogeneous atmo- spheres: RRTM, a validated correlated-k model for the longwave. J. Geophys. Res., 102, 16 663-16 682.

Morcrette, J.-J., S. A. Clough, E. J. Mlawer, and M. J. Iacono, 1998: Impact of a validated radiative transfer scheme, RRTM, on the ECMWF model climate and 10-day forecasts. ECMWF Tech. Memo. 252, Reading, United Kingdom, 48 pp.

Murphy, D. M., D. S. Thomson, A. M. Middlebrook, and M. E. Schein, 1998: In situ single-particle characterization at Cape Grim. J. Geophys. Res., 103, 16 485-16 491.

Nenes, A., S. N. Pandis, and C. Pilinis, 1998: ISORROPIA: A new thermodynamic equilibrium model for multiphase multicomponent inorganic aerosols. Aquat. Geochem., 4, 123-152.

Nordeng, T. E., 1994: Extended versions of the convective parameterization scheme at ECMWF and their impact on the mean and transient activity of the model in the tropics. ECMWF Tech. Memo. 206, Reading, United Kingdom, 42 pp.

Penner, J. E., and Coauthors, 2001: Aerosols, their direct and indirect effects. Climate Change 2001: The Scientific Basis, J. T. Houghton et al., Eds., Cambridge University Press, 298-248.

Ramanathan, V., P. J. Crutzen, J. T. Kiehl, and D. Rosenfeld, 2001: Aerosols, climate, and the hydrological cycle. Science, 294, 2119-2124.

Rasch, P. J., M. C. Barth, J. T. Kiehl, S. E. Schwartz, and C. M. Benkovitz, 2000: A description of the global sulfur cycle and its controlling processes in the National Center for Atmospheric Research Community Climate Model. J. Geophys. Res., 105, 1367-1386.

Ravishankara, A. R., 1997: Heterogeneous and multiphase chemistry in the troposphere. Science, 276, 1058-1066.

Roderick, M. L., and D. Farquhar, 2002: The cause of decreased pan evaporation over the past 50 years. Science, 298, 14101411.

Roeckner, E., and Coauthors, 2003: The atmospheric general circulation model ECHAM5. Part I: Model description. Rep. 349, Max Planck Institute for Meteorology, Hamburg, Germany, 127 pp. [Available online at http://www.mpimet. mpg.de.]

_ , and Coauthors, 2006: Sensitivity of simulated climate to horizontal and vertical resolution in the ECHAM5 atmosphere model. J. Climate, 19, 3771-3791.

Saarnak, C. F., 2001: A shift from natural to human-driven fire regime: Implications for trace-gas emissions. Holocene, 11, 373-375.

Schulz, M., G. de Leeuw, and Y. Balkanski, 2004: Sea-salt aerosol source functions and emissions. Emission of Atmospheric Trace Compounds, C. Granier, P. Artaxo, and C. E. Reeves, Eds., Kluwer, 333-359.

Seinfeld, J. H., and Coauthors, 2004: ACE-ASIA: Regional climatic and atmospheric chemical effects of Asian dust and pollution. Bull. Amer. Meteor. Soc., 85, 367-380.

Simmons, A. J., and J. K. Gibson, 2000: The ERA-40 project plan. ERA-40 Project Report Series 1, ECMWF, Reading, United Kingdom, 63 pp.

Stier, P., and Coauthors, 2005: The aerosol-climate model ECHAM5-HAM. Atmos. Chem. Phys., 5, 1125-1165.

Tegen, I., and A. A. Lacis, 1996: Modeling the particle size distribution and its influence on the radiative properties of mineral dust aerosol. J. Geophys. Res., 101, 19 237-19 244.

, S. P. Harrison, K. Kohfeld, I. C. Prentice, M. Coe, and M. Hermann, 2002: Impact of vegetation and preferential source areas on global dust aerosol: Results from a model study. $J$. Geophys. Res., 107, 4576-4597. 
Textor, C., and Coauthors, 2005: Analysis and quantification of the diversities of aerosol life cycles within AeroCom. Atmos. Chem. Phys. Discuss., 5, 8331-8420.

Tiedtke, M., 1989: A comprehensive mass flux scheme for cumulus parameterization in large-scale models. Mon. Wea. Rev., 117, 1779-1800.

Tompkins, A., 2002: A prognostic parameterization for the subgrid-scale variability of water vapor and clouds in large-scale models and its use to diagnose cloud cover. J. Atmos. Sci., 59, 1917-1942.

Twomey, S., 1974: Pollution and the planetary albedo. Atmos. Environ., 8, 1251-1256.

_ 1977: The influence of pollution on the shortwave albedo of clouds. J. Atmos. Sci., 34, 1149-1152.

Vignati, E., J. Wilson, and P. Stier, 2004: M7: A size resolved aerosol mixture module for the use in global aerosol models. J. Geophys. Res., 109, D22202, doi:10.1029/2003JD004485.
Vink, S., and C. Measures, 2001: The role of dust deposition in determining surface water distributions of $\mathrm{A} 1$ and $\mathrm{Fe}$ in the South West Atlantic. Deep-Sea Res., 48, 2782-2809.

West, J. J., A. S. Ansari, and S. N. Pandis, 1999: Marginal PM $_{2.5}$ : Nonlinear mass response to sulfate reductions in the eastern United States. J. Air Waste Manage. Assoc., 49, 1415-1424.

Wetzel, P., E. Maier-Reimer, M. Botzet, J. Jungclaus, N. Keenlyside, and M. Latif, 2006: Effects of ocean biology on the penetrative radiation in a coupled climate model. J. Climate, 19, 3973-3987.

WHO, 2003: Health aspect of air pollution with particulate matter, ozone and nitrogen dioxide. WHO Working Group Rep., 98 pp. [Available online at http://www.euro.who.int.]

Wilson, J., C. Cuvelier, and F. Raes, 2001: A modeling study of global mixed aerosol fields. J. Geophys. Res., 106, $34081-$ 34108 . 